\title{
Educação a Distância mediada pela Internet: Uma abordagem Interdisciplinar na Formação de Professores em Serviço
}

\author{
Rosane Aragón de Nevado ${ }^{1}$ \\ Marie Jane Soares de Carvalho ${ }^{1}$ \\ Crediné Silva de Menezes ${ }^{1,2}$ \\ ${ }^{1}$ Curso de Pedagogia a Distância - PEAD/FACED/UFRGS \\ ${ }^{2}$ Departamento de Informática - UFES
}

rosane.aragon@ufrgs.br, marie@pesquisadora.cnpq.br, credine@inf.ufrgs.br

Resumo: A realização cursos a distância baseada no uso intensivo de atividades cooperativas utilizando a Internet, requer uma nova concepção dos currículos e de ferramentas. Este artigo apresenta a concepção de um curso, o processo de preparação de recursos humanos e a concepção de ferramentas de apoio à interação. $O$ curso destina-se à formação em pedagogia de professores leigos de Escola Públicas do Rio Grande do Sul.

Palavras Chaves: Educação a distância, formação de professores, telemática e educação

Abstract: The achievement of long distance learning courses, based in the intensive use of cooperative activities utilizing the Internet, requires a new conception of the curriculums and the support of interactive tools. This article presents the conception of a course, the human resources preparation and the conception of computational tools. The course is addressed to the formation of teachers of public schools of Rio Grande do Sul State, Brazil.

Keywords: Long Distance Learning, teachers formation, telematics and education. 


\section{Introdução}

A formação do professor, como a de qualquer outro profissional, não se esgota com a conclusão de seu curso de graduação ou seu curso de nível médio. Trata-se de um processo continuado que alia a prática docente ao aperfeiçoamento constante por via de diferentes modalidades de estudo e reflexão, oferecidas pelas instituições de nível superior e fruto de parcerias com os sistemas mantenedores em função de políticas públicas bem definidas. Neste sentido, as inúmeras iniciativas desenvolvidas em anos mais recentes pelas Universidades Públicas do país são clara demonstração de que tais instituições estão traduzindo concretamente o compromisso de contribuir para a formação continuada dos professores brasileiros.

Ainda que a situação da região Sul seja distinta de regiões como o Norte e o Nordeste do país quanto à titulação em nível superior de professores que atuam nos anos iniciais do ensino fundamental, ainda há carências a serem supridas. Do total de docentes $(\mathrm{N}=45.515)$ nos anos iniciais do Ensino fundamental no Rio Grande do Sul, 57\% ( $\mathrm{N}=26.064)$ têm o Ensino Médio Completo, tem-se um contingente expressivo de professores em exercício que necessitam formação em nível de graduação.

Buscando responder mais efetivamente essa demanda e apoiada pelo conhecimento adquirido na área de Educação a Distância, dispõe-se hoje a FACED/UFRGS a implementar sua primeira experiência de formação acadêmica inicial em nível de graduação de professores à distância, qual seja, o Curso de Pedagogia: Licenciatura para os Anos Iniciais no Ensino Fundamental, oferecido a docentes em exercício nas escolas públicas.

O Curso busca superar a dicotomia apresentada pelos modelos convencionais de cursos de formação de professores, que teorizam sobre as transformações nas práticas educativas, sem que essas transformações sejam vivenciadas no próprio ambiente de formação. Para tal, é proposto um currículo com características interdisciplinares, o uso de metodologias interativas e um uso intensivo da Internet para desenvolvimento e acompanhamento das aprendizagens, quebrando os limites rígidos impostos pela concepção física e lógica que se tem de escola.

O projeto do Curso divide-se em dois momentos, um primeiro preparatório que contemplou a formação interna e a produção de materiais e um segundo momento, no qual se esta desenvolvendo o curso, tendo iniciado suas atividades em agosto de 2006.

\section{Princípios orientadores do curso}

A proposta do curso apóia-se em dois pressupostos: a) o de que os professores em efetivo exercício possuem formação inicial mínima obtida seja através da realização de Curso Normal Médio, seja através da experiência como docente, construída após o término do Ensino Médio; b) de que a oferta de novo curso de graduação que considere as condições reais de vida e trabalho dos professores e garanta a qualidade da formação em serviço abre a perspectiva de experimentação das possibilidades da EAD para os processos de aperfeiçoamento desses docentes.

Considerando a especificidade que deve caracterizar um processo de formação inicial e ao mesmo tempo continuada de professores, a organização curricular do Curso orienta-se pela inter-relação necessária entre o projeto pedagógico e os princípios orientadores do currículo. O que se nomeia é a relação imprescindível entre ambos ao traduzirem aquilo que se deseja (em "teoria") na prática deste curso.

A organização do currículo é proposta para além da tradicional divisão em disciplinas fechadas em si mesmas e em sequiências isoladas de trabalho docente. A 
idéia geradora do currículo deste Curso é instaurar Interdisciplinas que agregam e articulam os conhecimentos específicos teóricos e práticos em cada semestre. Para garantir essa articulação, são propostos Seminários Integradores.

Entende-se que a possibilidade inovadora da proposta se viabilizará na medida do abandono, pelos docentes do Curso e pelos próprios alunos-professores, da idéia de "domínio" sobre seus respectivos campos de saber e sobre seus espaços próprios de atuação e na disponibilidade de cada um e de todos em compreender as perspectivas da inter-comunicabilidade dos saberes e atuar interdisciplinarmente. A Figura 1 ilustra a dinâmica que articula os 3 princípios que norteiam a concepção do curso.

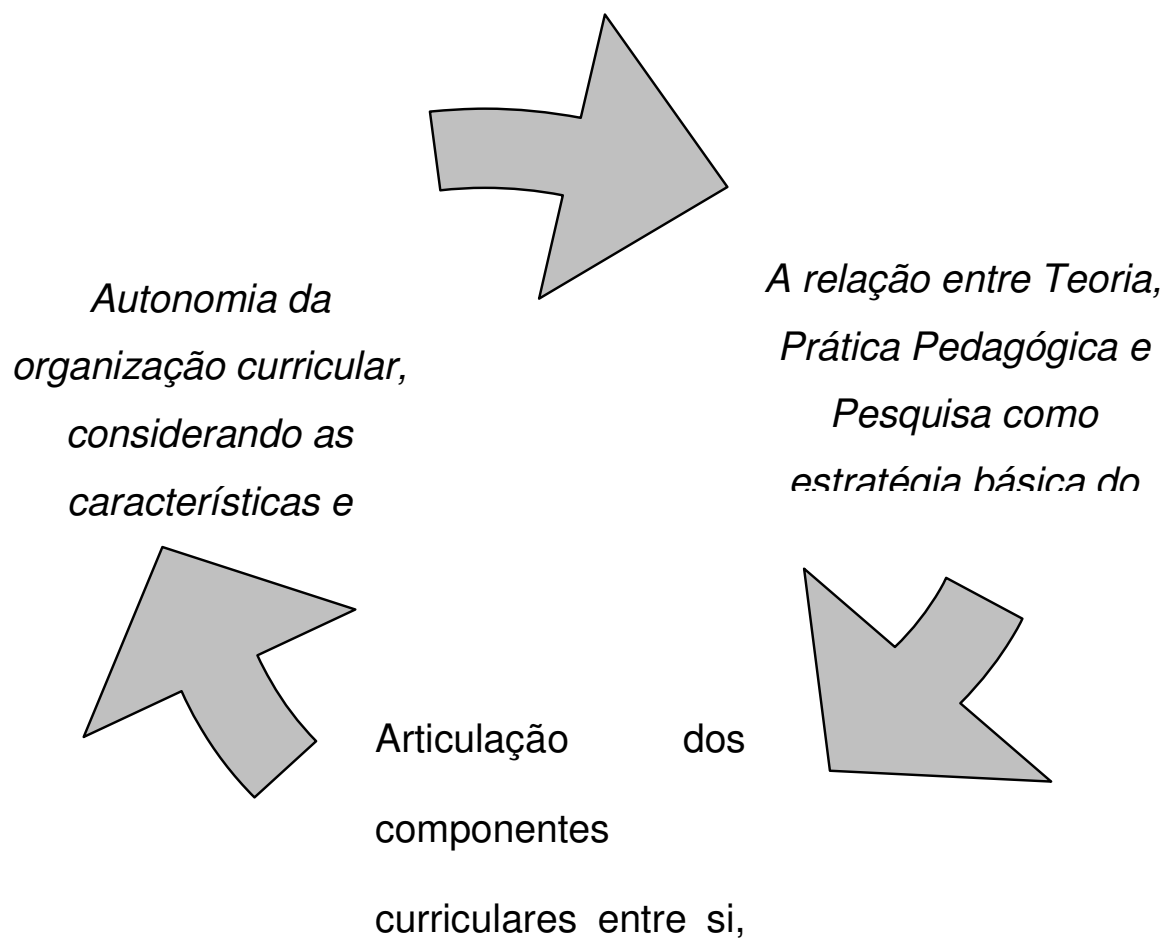

Figura 1 : Princípios norteadores do curso

\section{Organização do Curso}

O documento Diretrizes Gerais do Programa de Formação e Titulação de Professores Leigos (CEPE/UFRGS, 1999) esclarece aos cursos de licenciatura por ele abrangidos que sua estrutura curricular deve possuir uma identidade própria a partir da identidade do público-alvo, aproveitando suas experiências docentes, de forma a contribuir para a re-elaboração teórico-científica das mesmas. O mesmo documento recomenda que o exercício do trabalho pedagógico deve se dar de maneira coletiva, integrada e investigativa, o que implica na indissociabilidade entre ensino, pesquisa e extensão.

O curso será desenvolvido em oito eixos temáticos, sendo que cada eixo ocorrerá em um semestre acadêmico. Dentro de um eixo, que tem um grande tema norteador, as atividades se desdobram em interdisciplinas. A proposta é que as várias interdisciplinas prevejam atividades integradas e atividades específicas. Além da busca pela integração, 
em nível das interdisciplinas durante o decorrer do semestre, desenvolve-se um seminário integrador cuja intenção é fortalecer os entrelaçamentos.

Para garantir a comunicação entre alunos, professores, tutores e monitores, o desenho do curso propõe o seu desenvolvimento nas modalidades (i) a distância e (ii) presencial, tendo como base uma metodologia interativa e problematizadora. Essa metodologia considera: a formulação de problemas; o levantamento de respostas provisórias; o planejamento de situações experimentais; a testagem de hipóteses no desenvolvimento compartilhado de projetos interdisciplinares.

Como a proposta pedagógica do curso baseia-se na interdisciplinaridade, na construção cooperativa do conhecimento e na forte interação entre teoria e prática, o curso utiliza arquiteturas pedagógicas ancoradas em ferramentas de apoio ao trabalho cooperativo a distância, onde todos podem tomar conhecimento das práticas dos companheiros de curso e o livre acesso dos professores às atividades desenvolvidas pelos estudantes nas diversas atividades, sem a clássica barreira das disciplinas. Isto se estende também ao trabalho dos professores do curso, que estarão buscando a cada momento a realização de um trabalho integrado.

Desta forma, este Curso vem reforçar não só a importância atribuída à articulação dos componentes curriculares entre si, no semestre e ao longo do curso, mas também sua ligação com as experiências docentes, ou seja, com a prática pedagógica realizada nas escolas e classes onde as alunas-professoras desenvolvem a docência. Para tanto, é preciso adotar ações de planejamento e ensino, que possam atender a estas especificidades, a saber:

- Compartilhamento de disciplinas por professores oriundos de diferentes áreas de conhecimento e departamento;

- Trânsito constante entre teoria e prática, através da seleção de conteúdos e procedimentos de ensino;

- Eixo articulador por semestre, que deve orientar e constituir os enfoques temáticos das Interdisciplinas de cada período do Curso;

- Professor articulador do semestre, ou seja, um professor responsável pela concreta associação entre os demais professores e suas respectivas Interdisciplinas no semestre, bem como nos diferentes semestres entre si;

- Reuniões presenciais e on-line de planejamento conjunto das atividades do semestre com os professores articuladores dos eixos, para garantir a integração.

Nesta dinâmica interdisciplinar é importante explicitar o que se entende por cada denominação específica deste Curso. Os eixos articuladores são os organizadores do semestre e representam a direção do foco de abordagem em cada interdisciplina, atividade ou conteúdo específico. Por sua vez, as interdisciplinas estão contidas nos eixos articuladores e compreendem a abordagem organizativa de um tema amplo, que contem inúmeras possibilidades de enfoques temáticos e teórico-práticos. A interdisciplina se configura como um campo de abordagem e não como uma disciplina.

Em cada semestre letivo será desenvolvido o Seminário Integrador de Eixo que ocorrerá dentro da seguinte dinâmica:

- Um momento inicial presencial para apresentação e discussão das atividades integradoras, bem como, serão oferecidas Oficinas de Apropriação Tecnológica e outras atividades planejadas pelo coletivo do eixo;

- Atividades desenvolvidas a distância, via ambiente virtual e videoconferências, em continuidade às proposições do momento presencial; 
- Um momento presencial final para o fechamento das atividades do eixo, incluindo a discussão do webfólio do semestre.

\section{Formação dos docentes e tutores}

A formação inicial do corpo docente realizou-se nas modalidades presencial e a distância, perfazendo 80 horas. Posteriormente, a formação seguirá de forma continuada durante todo o curso, como apoio às atividades docentes.

A formação privilegiou a construção de conhecimento compartilhada e foi desenvolvida considerando o entrelaçamento de três dimensões: teórica, metodológica e tecnológica, propondo a formação de grupos de trabalho dentro dos eixos curriculares.

As atividades foram desenvolvidas tendo o ambiente virtual como apoio, tanto na modalidade presencial, quanto na modalidade a distância.

Objetivos da formação:

- Instrumentalizar os docentes para a produção de material pedagógico (material para a Internet, material impresso, uso de recursos, software, etc.)

- Possibilitar aos docentes a exploração de ambiente virtual de aprendizagem para que esses conheçam/explorem os seus recursos e discutam as possibilidades e limites desses recursos no Curso de Pedagogia a Distância;

- Estudar e criticar modelos de EAD, visando superar: a) os modelos transmissivos; 2) as dicotomias entre teoria e prática;

- Definir princípios pedagógicos e "desenhos" (arquiteturas) para os materiais a serem produzidos.

- Dentre as atividades desenvolvidas na formação, destacamos a exploração de recursos das TICS, a discussão dos modelos pedagógicos para EAD e a experimentação de formas de mediação das aprendizagens em contextos digitais.

Os tutores foram selecionados entre alunos de pós-graduação, nível mestrado e doutorado, prioritariamente com experiência em Educação a distância.

A formação inicial, realizada em 60 horas, visou:

- a discussão e apropriação dos princípios, metodologias e modos de funcionamento do curso;

- a exploração dos materiais pedagógicos e do ambiente virtual de aprendizagem para que esses conheçam e explorem os seus recursos e discutam as possibilidades e limites desses recursos no curso.

\section{Produção de material pedagógico na perspectiva interdisciplinar}

O curso será desenvolvido mediante materiais interativos na web, substituindo o uso dos tradicionais "fascículos" na EAD. O desenvolvimento dos materiais pedagógicos em todos os eixos da matriz curricular foi orientado para promover situações de aprendizagem interativas, utilizando-se criativamente das TICs. Os materiais produzidos para apoio ao curso não se limitaram à seleção e encaminhamento de longos textos a serem lidos e comentados pelos alunos, mas sim buscando ensejar:

- o envolvimento efetivo dos alunos-professores em situações problemáticas;

- a construção de novo conhecimento;

- o desenvolvimento do raciocínio crítico na busca de soluções criativas;

- a adaptação dos conteúdos aos problemas locais; 
- a discussão presencial ou via rede, entre os alunos-professores, inclusive com os demais professores colegas de escola;

- a elaboração de projetos de aprendizagem a serem desenvolvidos pelos alunosprofessores em suas próprias classes.

Entre os principais critérios destacamos a aplicabilidade dos materiais em que pesam:

- a simplicidade de procedimentos;

- o não abuso de efeitos visuais, puramente "decorativos";

- a consideração de que não se deve incluir um instrumental tecnológico demasiado complexo ou de difícil utilização;

- a inclusão de orientações precisas para a realização da atividade, especialmente no início do curso (Eixos 1 e 2), indicando os passos a cumprir de modo a favorecer o desenvolvimento da autonomia dos professores-alunos;

- as atividades e experimentos propostos nos materiais pedagógicos dirigidos à prática em sala de aula e seu entorno com objetivo de personalizar os processos de aprendizagem.

A elaboração de materiais pedagógicos envolveu 43 docentes especialistas responsáveis pelos materiais referentes às diversas áreas de conhecimento envolvidas no curso de pedagogia e, ainda 41 docentes voluntários que auxiliaram essa produção. Coube, também, aos docentes responsáveis pelos conteúdos discutir e orientar a equipe de técnicos na produção de páginas web, apresentações, animações, formulários etc.

\section{Ferramentas de Apoio à Metodologia Interacionista}

Neste primeiro semestre do curso, utilizamos o ambiente ROODA (www.ead.ufrgs.br/rooda), plataforma oficial da UFRGS para educação a distância, juntamente com um ambiente de blog (www.blogger.com), um ambiente para autoria cooperativa (pbwiki.com), um ambiente para compartilhamento de fotos (www.bubbleshare.com) e um ambiente para compartilhamento de vídeos (www.youtube.com)

O desenvolvimento de atividades, dentro de uma perspectiva construtivista, requer o apoio de ferramentas que facilite o exercício da autoria, o trabalho cooperativo e o desenvolvimento da autonomia. Com esse objetivo, concebemos e estamos desenvolvendo um conjunto complementar de ferramentas computacionais, que facilite aos professores a elaboração de atividades interativas. A seguir apresentamos algumas dessas ferramentas.

6.1 Ambiente para esclarecimento de dúvidas: o estudante de cursos a distância, em virtude da natureza assíncrona das interações, requer um tratamento diferenciado com relação aos pedidos de esclarecimento. Considerando que os ambientes virtuais oferecem múltiplas oportunidades para que o registro de anotações, os estudantes podem manifestar suas necessidades de esclarecimento em lugares diversos e inusitados. Embora pareça bastante convidativo, manifestar as necessidades de esclarecimento em diferentes lugares não é muito prático. Nem para o estudante nem para o corpo docente (professores e tutores). Neste sentido concebemos um ambiente específico para o esclarecimento dos estudantes que facilita o acompanhamento do processo. O ponto de partida é a manifestação de um aluno, evidenciando uma dúvida, com respeito a uma interdisciplina. Automaticamente o sistema direciona esta questão 
para o tutor da interdisciplina, responsável pelo acompanhamento daquele aluno. A partir daí é estabelecido um ciclo de conversação para o esclarecimento, que é finalizado quando o estudante avisa que já está esclarecido ou que ele deseja suspender $\mathrm{o}$ ciclo. $\mathrm{O}$ tutor, em qualquer momento pode se sentir sem argumentos para prosseguir o esclarecimento e, portanto transferir a responsabilidade para o professor. A Figura 2 apresenta uma das interfaces para o sistema de esclarecimento de dúvidas.

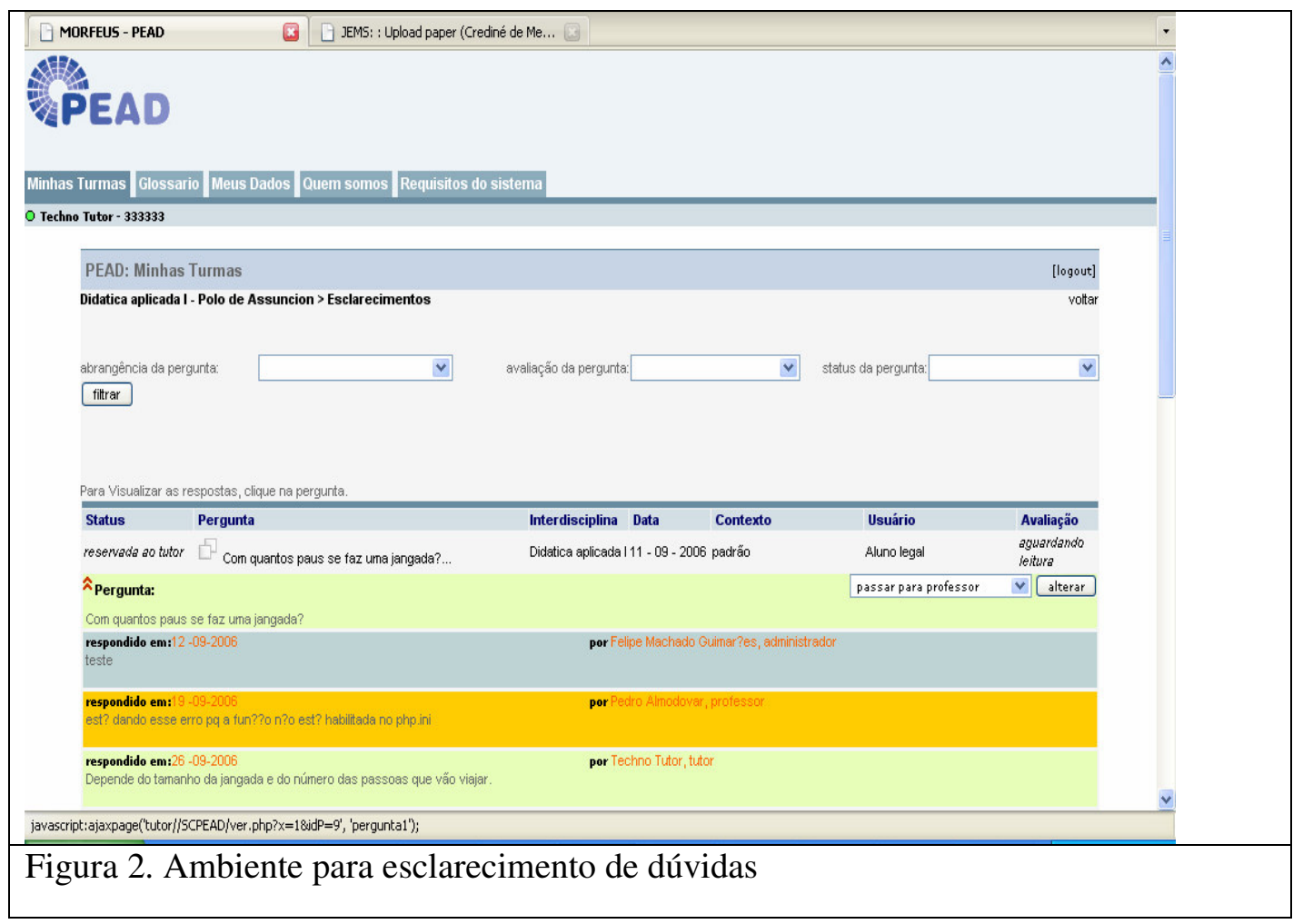

6.2 Ambiente para autoria de trilhas virtuais: um tipo de atividade bastante enriquecedor é a realização de trilhas virtuais (Nevado, Carvalho, Menezes, 2005). A realização de uma trilha consiste em uma atividade lúdica, a ser explorada com o uso da internet, onde a aprendizagem ocorre de forma incidente. Em geral, podemos usar trilhas virtuais para a aprendizagem de assuntos, tidos como maçantes, cujo envolvimento dos estudantes é baixo. Neste sentido, uma trilha consiste de um mapa, onde se distribuem estações, que podem ser ativadas a partir do clicar do mouse. Em cada estação existe a descrição de uma atividade, eventualmente com textos de apoio e referências e o convite à postagem de um ou mais arquivos resultantes da sua realização. $\mathrm{O}$ uso intensivo de trilhas, requer a um ambiente onde os estudantes e professores possam produzi-las, sem conhecimento de programação.

6.3 Ambiente para autoria de júris virtuais: No estudo de certos assuntos, principalmente quando desejamos ajudar os alunos a dominarem a arte da argumentação, podemos trabalhar com júris. Em um júri temos três grupos de participantes: a favor, contra e juizes. Definidos os times, durante um determinado período, os times a favor e contra, devem apresentar seus argumento. Findo o prazo, as postagens são encerradas e o time dos juizes apresenta um veredicto a partir das 
argumentações apresentadas. Um ambiente de autoria permite o cadastramento, a abertura e o desenvolvimento de um júri.

6.4 Ambiente para autoria de textos interativos: Algumas atividades, requerem a leitura de textos, que são seguidas de questões para as quais o estudante é convidado a apresentar as suas considerações. Essas considerações devem ser armazenadas e disponibilizadas para a leitura de todos os participantes. Um ambiente de autoria permite o cadastramento, a criação e o acompanhamento de um texto interativo, provendo suporte de banco de dados. A disponibilização do ambiente permite a criação de novas atividades pelo professor sem que seja necessário o domínio de programação.

6.5 Glossário multicontextual: A criação de um glossário, quando desejamos construir conhecimento sobre um determinado tema, tem se mostrado de grande contribuição. A construção é cooperativa, cada estudante pode introduzir novas palavras, novas definições e comentários às definições dos demais participantes. Os professores podem introduzir novos contextos, sempre que um tema novo surge. Quando um estudante considera que após o debate, uma definição que ele postou, está vencida, ou seja, o seu entendimento agora é outro, ele pode indicar, marcando a definição com o status de "superada". A Figura 3 apresenta a interface básica do glossário. Para cada palavra, existe um link para as definições de cada contexto. Para acessar o google ou a wikipédia, o sistema gera automaticamente um link para cada palavra constante no glossário.

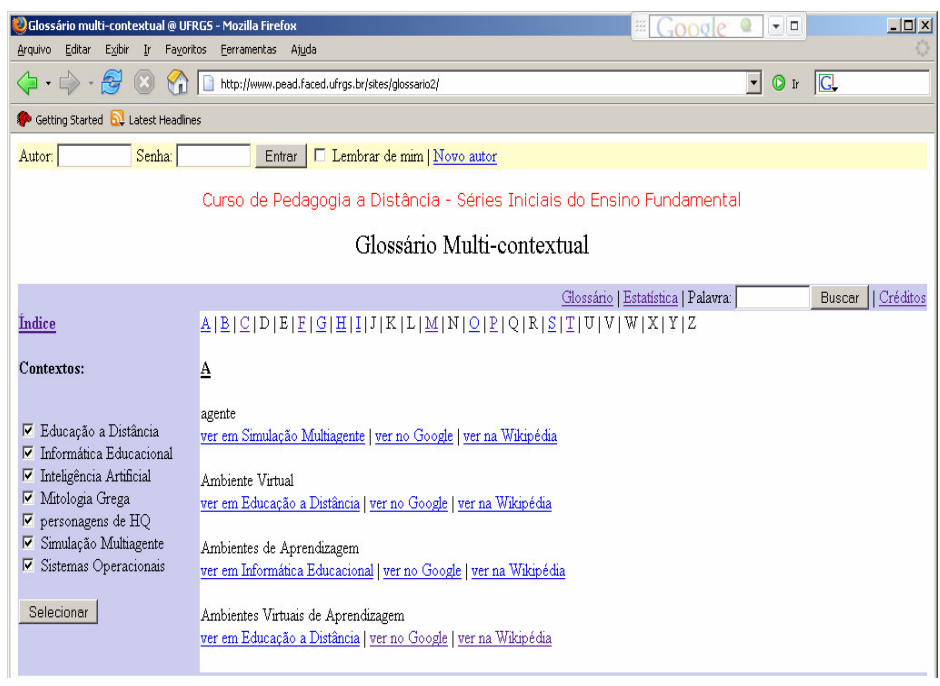

Figura 3 - Glossário multicontextual para construção e conceitos

6.6 Ambiente para Definição, Coleta e Análise de Dados: O acompanhamento das atividades dos estudantes, o levantamento de conhecimento, as pesquisas sobre o desenvolvimento das aprendizagens pelos docentes, além de atividades de aprendizagem baseadas na pesquisa de campo, requerem a disponibilização de ferramentas adequadas. Para este fim, visando as características do curso, foi customizado o PHP Surveyor, um software livre, disponível em www.sourceforge.org. Na Figura 3 apresentamos a tela de cadastramentos e definição de uma coleta de dados. 
6.7 Workshop Virtual: a realização de atividades coletivas, que incentivem e proporcionem a construção cooperativa do conhecimento, pode ser materializada através da elaboração e publicação de trabalhos acadêmicos. O debate é realizado através de um fórum associado a cada trabalho. $\mathrm{O}$ ambiente permite o cadastramento de eventos, a publicação de trabalhos e o debate associado a cada trabalho.

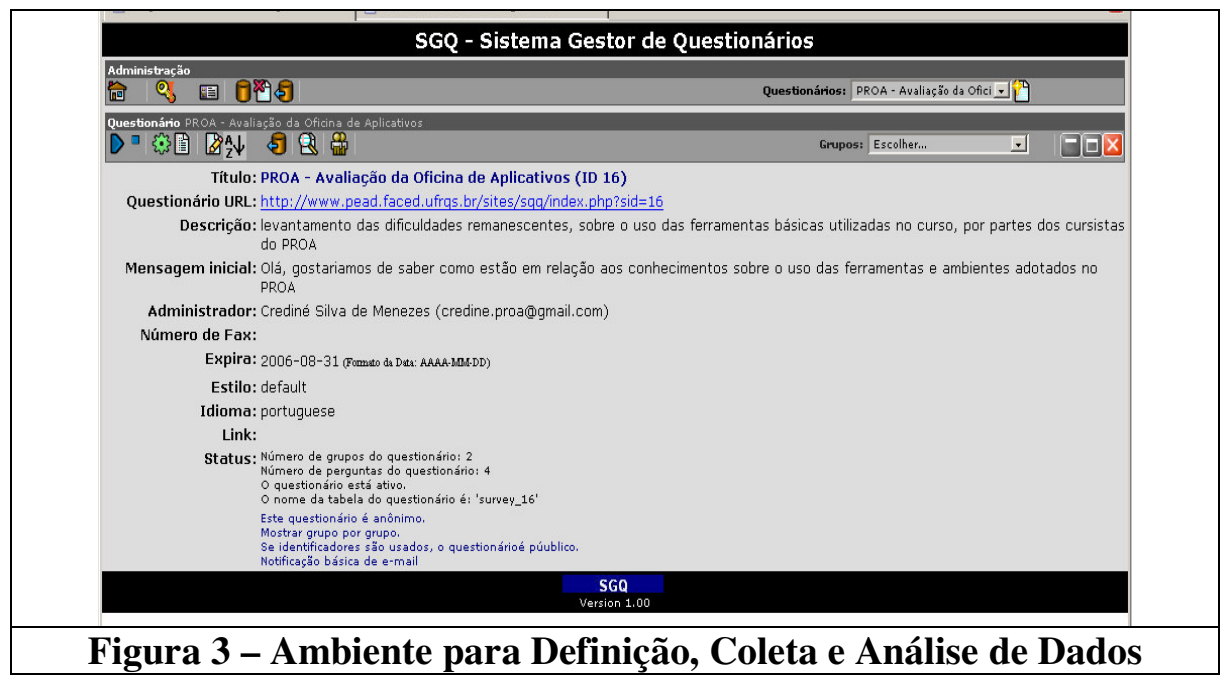

\section{Princípios norteadores para Organização do Espaço Virtual de Aprendizagem}

Segundo estudos como os de Deschênes (1998) e Riaño (1996), bem como por trabalhos desenvolvidos na Universidade Federal do Rio Grande do Sul - UFRGS (Fagundes, 1993; Nevado et alli, 2001, entre outros), as perspectivas de mudança não residem apenas na disponibilização de suportes tecnológicos potentes, mas em novas formas de conceber e praticar a educação, entendendo que o conhecimento nasce do movimento, da dúvida, da incerteza, da necessidade de busca de novas alternativas, do debate, da troca.

Nessa concepção, que chamamos construtivista, temos que:

- O conhecimento não é um produto fixo e acabado, ele é construído num contexto de trocas, mediante um tensionamento constante entre o conhecimento atual ("certezas atuais, provisórias") e as "dúvidas" que recaem sobre essas certezas, conduzindo ao estabelecimento de novas relações ou conhecimentos (novas certezas, ainda que também temporárias);

- Ao professor cabe a função de promover a aprendizagem, estimular o diálogo, provocar a emergência de situações de dúvidas (desequilíbrios) e apoiar as reconstruções (novos conhecimentos);

- Ao aluno cabe uma postura ativa, a ele cabe experimentar, compartilhar, criar, interagir para compreender.

A aplicação dessas idéias à organização dos ambientes virtuais de aprendizagem tem como conseqüência o abandono da perspectiva de "ensino na rede" em favor de processos de "aprendizagem em rede", caracterizadas por enfatizar; 
- A formação de comunidades virtuais, redes de interações e formas renovadas de formação continuada, mudando o foco do ensino para a construção de aprendizagens cooperativas;

- A ampliação dos "espaços" e a criação de novos "espaços" de aprendizagem criação de webfólios, páginas web, uso de blogs, ferramentas de comunicação, dentro e fora das instituições de ensino;

- O estabelecimento de novas temporalidades decorrentes das comunicações assíncronas, como o uso de fóruns;

- Flexibilizações nas relações entre professores e alunos e entre os grupos de alunos, buscando-se o desenvolvimento de atividades e projetos partilhados, nos quais o professor funcionará como um parceiro experiente e não como um centralizador de saberes;

- A disponibilização de uma diversidade de informações que podem ser reinterpretadas e reelaboradas, contribuindo para a formação de uma dimensão coletiva da inteligência, mediante processos de autoria, de novas formas de escrita e leituras coletivas, nas quais os textos são reconfigurados, aumentados e conectados uns aos outros por meio de ligações hipertextuais.

Nessa concepção, os ambientes virtuais de aprendizagem assumem uma nova organização, prevendo a articulação dos espaços, buscando superar as fragmentações disciplinares. Os instrumentos de comunicação são sintonizados com a criação de práticas interdisciplinares e com a busca de relações dialógicas entre professores e alunos.

\section{Avaliação da aprendizagem apoiada por webfólios}

O processo de avaliação continuada consistirá em dinamizar oportunidades de açãoreflexão sobre a prática docente e os conhecimentos adquiridos. Será o acompanhamento permanente de docentes da FACED e de docentes designados pelas demais parceiras, para sua efetivação conjunta. Para tal, Propomos uma adaptação dos fundamentos da proposta de portfólio educacional (Carvalho e Sartori, 2005), aliada as experiências desenvolvidas no LEC/UFRGS, no acompanhamento e na avaliação da formação dos professores-alunos. (Nevado et alli, 1999; Costa et alli, 1998; Nevado et alli, 2004).

O webfólio é, sobretudo, um instrumento de auto-avaliação e de avaliação coletiva. Dessa forma, a avaliação incorpora-se ao processo de construção do conhecimento, abandonando o seu caráter controlador, punitivo ou mesmo reforçador e passa a ser um elemento favorecedor das tomadas de consciência. Os erros, que costumeiramente são encarados como resíduos a serem eliminados, serão entendidos como "erros construtivos" na medida em que esses tornam-se "observáveis" para o sujeito e, dessa forma, tornam-se fontes importantes de reconstrução.

Os webfólios apresentam-se como excelentes suportes ä avaliação participativa, na qual cada sujeito será avaliado por si mesmo (auto-avaliação), pelos seus colegas e pelos professores, dentro de critérios estabelecidos de forma cooperativa pelo grupo. Para sustentar esse processo participativo, os webfólios deverão oferecer facilidades para a apresentação das evidências ou "testemunhos" da aprendizagem na sua dimensão 
processual, desde as perturbações que desequilibram as certezas do sujeito, até a criação de novas formas de pensar, decorrentes da construção de novos instrumentos cognitivos.

Seis questionamentos básicos guiam a elaboração do webfólio: i) O que é aprendizagem? ii) O que valorizo na aprendizagem? iii) Quais são os meus objetivos como educador? iv) Que evidências traduzem a forma como trabalho a aprendizagem? v) Que resultados indicam que os objetivos foram alcançados? vi) Que práticas e discursos dos estudantes refletem os valores privilegiados e acordados?

A busca para responder a esses desafios e elaborar um portfólio educacional tem como propósito fortalecer o desenvolvimento continuado de cada um na relação com os outros e, sobretudo, organizar, esclarecer e comunicar o processo vivenciado durante a formação. O portfólio educacional busca refletir a fusão entre processo e produto. É um artefato que mostra as realizações em processo. De um modo geral, o portfólio educacional pode ser visto como um memorial, um registro qualificado, diferentemente de um currículo em que simplesmente nomeamos o que fizemos e o que foi certificado.

\section{Considerações Finais}

Tendo como princípio norteador a compreensão da dinâmica social e da rede de relações que cria e sustenta, assim como do espaço que nela ocupa a educação, o Curso de Licenciatura em Pedagogia Anos Iniciais do Ensino Fundamental, visa como princípio e fim preparar o professor para a meta reflexão permanente e a recriação das práticas, ao ampliar o conhecimento e o pensamento sobre o fazer pedagógico. É nesta perspectiva de meta reflexão, como ensaio e experimento presente numa visão prospectiva, que se pode vislumbrar e exigência máxima da educação: a formação e auto-formação.

\section{Referências Bibliográficas}

Brasil, Ministério da Educação (1996) Lei de Diretrizes e Bases da Educação Nacional. Lei no. 9.394 de 20 de dezembro de 1996.

Brasil, Ministério da Educação, Instituto Nacional de Estudos e Pesquisas Anísio Teixeira. (1999) "Doc. Norteador, Grupo Tarefa da Licenciatura, SESU/MEC", http://www.inep.gov.br, Agosto.

Carvalho, M. J. S. and Sartori, L. P. (2005), Portfólio Educacional: Proposta Alternativa de Avaliação - Guia Didático, Porto Alegre: Editora da UFRGS.

Kuenzer, A. Z. A (1998) Formação de educadores no Contexto das Mudanças no Mundo do Trabalho: Novos Desafios para as Faculdades de Educação. In Educação \& Sociedade, v. 63, pages 105-111

Nevado, R.A., Basso, M.V.A., Menezes, C.S. Webfólio: uma proposta para Avaliação na Aprendizagem Conceitos, estudos de casos e suporte computacional, Simpósio Brasileiro de Informática na Educação, Manaus-AM, 2004.

Costa, I. T; Fagundes, L. C; Nevado, R. A. Projeto TecLec- Modelo de uma Nova Metodologia em EAD incorporando os Recursos da Telemática. In: Informática na Educação- Teoria e Prática. Porto Alegre, 1998. v.1 n.1.p.83-100.

Nevado, R. Magdalena, B; Costa, I. Formação de Professores multiplicadores: nte2@projetos.cooperativos.ufrgs.br. Revista Informática na Educação: Teoria e Prática. V2 n 2 out 1999. 